\title{
Thermal and catalytic pyrolysis of plastic waste
}

\author{
Débora Almeida ${ }^{1}$ and Maria de Fátima Marques ${ }^{1 *}$ \\ ${ }^{1}$ Instituto de Macromoléculas Eloisa Mano, Universidade Federal do Rio de Janeiro - UFRJ, \\ Rio de Janeiro, RJ, Brasil \\ *fmarques@ima.ufrj.br
}

\begin{abstract}
The amount of plastic waste is growing every year and with that comes an environmental concern regarding this problem. Pyrolysis as a tertiary recycling process is presented as a solution. Pyrolysis can be thermal or catalytical and can be performed under different experimental conditions. These conditions affect the type and amount of product obtained. With the pyrolysis process, products can be obtained with high added value, such as fuel oils and feedstock for new products. Zeolites can be used as catalysts in catalytic pyrolysis and influence the final products obtained.
\end{abstract}

Keywords: catalytic pyrolysis, fuel oils, thermal pyrolysis, zeolites.

\section{Introduction}

Plastics are materials that offer a fundamental contribution to our society, due to its versatility and relatively low cost. As a result of this contribution, a large amount of plastic waste is generated due to the increase in its production each year. This increase in the amount of waste does cause some environmental problems, since plastics do not degrade quickly and can remain in the environment for a long time $e^{[1-5]}$. A large part of this waste is disposed of in landfills or is incinerated ${ }^{[6,7]}$.

However, the plastic waste are bulkier than other organic residues and thus occupy massive space in landfills and therefore the proper disposal and incineration have high costs. Furthermore, incineration of these waste plastics results in environmental problems due to increased emission of harmful compounds ${ }^{[2,6-8]}$.

It is necessary for more sustainable solutions that incineration and disposal in landfills are researched and developed ${ }^{[4]}$. Thus, much research in the area of recycling and reuse of these post-consumed polymers have been carried out in order to produce raw materials and energy ${ }^{[1,3,7]}$.

The various types of recycling are good options to control the increase of plastic waste, because they are environmentally friendly when compared with incineration and disposal in landfills. In fact, from recycling it is possible to recover raw materials, energy and fuel while minimizing the consumption of natural resources and raw materials. When these products and energy are recovered, the environmental impacts of industrial activity are reduced ${ }^{[1,3,9,10]}$.

Municipal waste plastics are heterogeneous, unlike industrial. For homogeneous plastic waste, the repelletization and remoulding can be a simple and effective means of recycling. However, when these wastes are heterogeneous and consist of mixtures of resins, they are unsuitable for such recovery. In this case, other forms of recycling ${ }^{[11]}$ are necessary. Each recycling method provides a number of advantages that make them beneficial for local and specific applications ${ }^{[12]}$. Appropriate treatment of plastic waste is an important question for waste management, due to energy, environmental, economic, and political ${ }^{[11]}$ aspects.
The plastics recycling methods, in accordance with ASTM D5033-00, are divided into four types according to the final result, one of them being the tertiary or chemical recycling. In this type of recycling chemical degradation leads to production of liquid fuels and chemicals with high added value from waste plastic fragments or segregated ${ }^{[2,8,13,14]}$.

One of the tertiary recycling methods is pyrolysis. This process can be thermal or catalytic and is a promising alternative that allows the conversion of polymers into gas and liquid hydrocarbons ${ }^{[4,15,16]}$.

Pyrolysis is a process with relatively low cost from which a wide distribution of products can be obtained. In the process of pyrolysis, where heating occurs in the absence of oxygen, the organic compounds are decomposed generating gaseous and liquid products, which can be used as fuels and / or sources of chemicals. Meanwhile, the inorganic material, free of organic matter, remains unchanged under the solid fraction and can be recycled later ${ }^{[17]}$.

The thermal pyrolysis requires high temperatures, which often results in products with low quality, making this process unfeasible. This occurs because the uncatalyzed thermal degradation gives rise to low molecular weight substances, however in a very wide range of products ${ }^{[13,15,16]}$.

This method can be improved by the addition of catalysts, which will reduce the temperature and reaction time and allow the production of hydrocarbons with a higher added value, such as fuel oils and petrochemical feedstocks ${ }^{[4,11,18-21]}$. That is, the use of catalysts gives an added value to the pyrolysis and cracking efficiency of these catalysts depends both on its chemical and physical characteristics. These particular properties, promote the breaking of C-C bonds and determine the length of the chains of the products obtained ${ }^{[17,22]}$.

For Brazilian cities, the percentage of high and low density polyethylene (HDPE and LDPE, respectively), polyethylene terephthalate (PET), Poly(vinyl chloride) (PVC) and polypropylene (PP) found in municipal solid wastes are $89 \%$ and the other polymers account for the other $11 \% 0^{[13]}$. 
Therefore, polyolefins (PE, PP and their copolymers) are the most widely used thermoplastics for several applications and are most of the polymeric residues, that make up $60-70 \%$ of municipal solid waste ${ }^{[23]}$.

Tertiary recycling of plastic waste containing PVC releases hydrogen chloride, which causes corrosion of the pyrolysis reactor and formation of organochlorine compounds ${ }^{[23]}$. The presence of chlorine is very harmful for use as fuel in the pyrolysis liquid products obtained ${ }^{[24]}$. Although plastic waste may be considered economical sources of chemicals and energy, recycling of mixed plastic waste containing PVC not only result in the formation of volatile organic compounds in products, also in the emission of pollution when they are applied ${ }^{[23]}$.

Moreover, PET may be mechanically recycled obtaining fibers for carpets, clothes and bottles. The products obtained in this recycling are of high quality that can be compared with virgin polymer ${ }^{[12]}$. Therefore, PET and other special polymers should be removed from municipal waste by mechanical recovery, which is economically viable.

\subsection{Pyrolysis}

The tertiary or chemical recycling includes a variety of processes that enable the generation of high value products such as fuel or chemicals ${ }^{[11,16,19-21,25-27]}$.

In this method, the plastic waste is processed to produce basic petrochemical compounds, which can be used as raw material for new plastics. This process has the advantage of working with mixed and contaminated plastics ${ }^{[12,18,20,27]}$.

Recently, much attention has been directed to chemical recycling, particularly the uncatalyzed thermal cracking (thermolysis), catalytic cracking and steam decomposition, as methods for producing various hydrocarbon fractions in the range of fuel, from solid waste plastics ${ }^{[12]}$.

In the case of polymers, pyrolysis stands out as tertiary recycling method, however this cracking gives rise to low molecular weight substances, however unfortunately in a very wide range of products, in the case of non-catalyzed thermal decomposition ${ }^{[1,13,15,16,18,26]}$. The pyrolysis can be carried out at different temperatures, reaction times, pressures, in the presence or absence of catalysts and reactive gases. The pyrolysis process involves the breaking of bonds, and is generally endothermic and hence the supply of heat is essential to react the material ${ }^{[28]}$. In polymeric samples, the decomposition process may occur through the elimination of small molecules, chain scission (depolymerization) or random cleavage ${ }^{[29]}$.

In the pyrolysis process, the sample is heated in the absence of oxygen and the organic compounds are decomposed generating gaseous and liquid products. On the other hand, the inorganic part of the sample, free from organic matter remains practically unchanged in the solid fraction enabling their separation and recovery for subsequent reuse. Therefore, the pyrolysis is an attractive alternative technique for recycling waste plastics recycling ${ }^{[2,8,17,24,30]}$.

Thermal pyrolysis involves the decomposition of polymeric materials by means of temperature when it is applied under inert atmospheric conditions. This process is usually conducted at temperatures between 350 and $900{ }^{\circ} \mathrm{C}$.
In the case of polyolefins, which make up much of urban waste plastics, the process proceeds through random cleavage mechanism that generates a heterogeneous mixture of linear paraffins and olefins in a wide range of molar masses ${ }^{[11,18,20,21]}$.

On the other hand, the catalyzed pyrolysis promotes these decomposition reactions at lower temperatures and shorter times, because of the presence of catalysts that assist in the process. Thus, the catalytic pyrolysis presents a number of advantages over thermal, such as lower energy consumption and product formation with narrower distribution of the number of carbon atoms, which may be directed to aromatic hydrocarbons with light and high market value ${ }^{[11,18-21,26]}$.

The kinetics of degradation and the pyrolysis mechanism are still being studied and discussed. Degradation has a very complex mechanism, so adequate description of decomposing a mixture of polymers is difficult, even more so in the presence of catalysts and a process with several stages ${ }^{[7,30]}$. In order to solve this problem there are some methods based on the mass loss curve during pyrolysis.

Thermogravimetric analysis (TGA) is a method that can be used to determine the loss of mass and kinetic parameters. Thermogravimetric analysis of pyrolysis involves the thermal degradation of the sample in an inert atmosphere obtaining simultaneously the weight loss values of the samples with increasing temperature at a constant heating rate ${ }^{[4,21,31]}$.

Most of the techniques that are used to monitor the reactions, both for the identification of products of the gas phase and by thermogravimetric analysis, will only detect the reaction when the molecules of the products become small enough to evaporate in the gas fraction and can be observed as gas fraction or by means of mass loss of the initial sample. Is possible to follow the reaction from the beginning, since each broken link consume certain amount of energy. Thus, by measuring the heat flow into the sample during the reaction (using for example the calorimeter DSC method), it is possible to measure the rate of broken bonds occurring in the sample ${ }^{[4]}$.

The reaction rates and other kinetic parameters of the degradation of the polymer are dependent on the chemical structure of these polymers. Generally the $\mathrm{CC}$ bonds of the polymer backbone are broken forming a higher degree of branching structures, due to the lower thermal stability of the tertiary carbon atom. Moreover, the mechanism may also be affected by contaminants. The actual reason for the differences between the rates of degradation of the macromolecules has been explained by the distortion of electron density from the degraded polymer, which depends primarily on the side group linked to the main chain of the macromolecule. For this reason, polypropylene (PP) is less stable than polyethylene (LDPE, HDPE or LLDPE), for example ${ }^{[7]}$.

The mechanism of degradation of polymers has generally been described as free radical in the case of a thermal process without catalyst. However, when catalysts are used, it is generally ionic mechanism ${ }^{[7]}$.

When catalysts are utilized in the pyrolysis occur two kinds of decomposition mechanisms simultaneously: thermal cracking, which in turn can follow different mechanisms (random chain scission, scission the end of the chain and / or elimination of side groups) and catalytic cracking 
(carbenium ions adsorbed on the catalyst surface, beta scission and desorption). As a result, a wide variety of products is generated, which in turn will react with each other resulting in a countless number of possible reaction mechanisms ${ }^{[30]}$.

For the pyrolysis of polyolefins, the degradation mechanism occurs by random chain scission, where free radicals are generated propagating chain reactions and thus resulting in the cracking of polymers in a wide range of hydrocarbons that make up liquid and gaseous fractions ${ }^{[32]}$. Several factors influence the process and the most important are: residence time, temperature and the type of pyrolysis agent. When the residence time and temperature increase, the composition of the obtained product shifts to more thermodynamically stable compounds ${ }^{[2,8,20,32]}$.

The pyrolysis products can be used as an alternative fuel or as a source of chemicals ${ }^{[30]}$. The composition of the product also depends on the presence of catalysts (including concentrations and types). Higher temperatures decrease the yield of hydrogen, methane, acetylene and aromatic compounds, whereas lower temperatures favor the generation of gas products ${ }^{[32]}$.

Previous experiments to evaluate the polymer degradation process are important because they provide information on the feasibility of recycling these polymers raw materials and even fuels. However, most studies are focused on pyrolysis of pure polymers and unmixed ${ }^{[7]}$.

\subsubsection{Thermal pyrolysis}

The pyrolysis of waste plastics involves the thermal decomposition in the absence of oxygen / air. During the pyrolysis, the polymer materials are heated to high temperatures and thus, their macromolecules are broken into smaller molecules, resulting in the formation of a wide range hydrocarbons. The products obtained from the pyrolysis can be divided into non-condensable gas fraction, liquid fraction (consisting of paraffins, olefins, naphthenes and aromatics) and solid waste. From the liquid fraction can be recovered hydrocarbons in the gasoline range (C4-C12), diesel (C12-C23), kerosene (C10-C18) and motor oil $(\mathrm{C} 23-\mathrm{C} 40)^{[1,3,18,20,33-35]}$.

The thermal cracking usually produces a mixture of low value hydrocarbons having a wide variety of products, including hydrogen to coke. In general, when the pyrolysis temperature is high, there is increased production of non-condensable gaseous fraction and a lower liquid fuels such as diesel. The yield and composition of the products obtained are not controlled only by the temperature but also the duration of the reaction ${ }^{[33]}$.

The thermal pyrolysis proceeds according to the radical chain reactions with hydrogen transfer steps and the gradual breakdown of the main chain. The mechanism involves the stages of initiation, propagation and / or free radical transfer followed by $\beta$ chain scission and termination ${ }^{[20,34,36]}$. This mechanism provides many oligomers by hydrogen transfer from the tertiary carbon atom along the polymer chain to the radical site ${ }^{[18]}$. The thermal cracking is more difficult for the high density polyethylene (HDPE), followed by the low density (LDPE) and then by polypropylene $(\mathrm{PP})^{[20]}$. This is due to high content of tertiary carbons of PP.
The initiation step comprises homolytic breaking of carbon-carbon bond, either by random chain scission as by cleavage at the end of the chain, resulting in two radicals ${ }^{[36,37]}$. For PP and PE the chain scission occurs at random ${ }^{[37]}$.

This step is followed by hydrogen transfer reactions intra / intermolecular forming more stable radicals secondary. These intermediate radicals can be submitted to break the carbon-carbon bond by scission $\beta$ to produce compounds saturated or with unsaturated terminal and new radicals. The transfer of intra / intermolecular hydrogen depend on the experimental conditions, the first of which leads to an increase in the production of olefins and diolefins, paraffins results in the second ${ }^{[34,36,37]}$.

The termination reactions can occur, for example, by disproportionation, which can produce different olefins and alkanes or a combination of radicals can lead to the same products. Branched products can be formed from the interaction between two secondary radicals or between a secondary radical with a primary ${ }^{[36,37]}$.

As a consequence of these mechanisms, the thermal pyrolysis leads to a wide distribution of hydrocarbon, a C5-C80 range, each fraction being mainly composed of diene, 1 -olefin and n-paraffin. At high temperatures hydrogen is formed in significant amounts. Products obtained by thermal cracking are of limited commercial value, especially being applied as fuel. For heavy oils, it has been proposed its use as a wax ${ }^{[36]}$. Obtaining this wide range of products is one of the major drawbacks of this technique, which requires temperatures of $500{ }^{\circ} \mathrm{C}$ to $900{ }^{\circ} \mathrm{C}$. These factors severely limit its applicability and increase the cost of recycling raw material of plastic waste ${ }^{[23]}$.

\subsubsection{Catalytic pyrolysis}

The thermal pyrolysis requires high temperatures due to the low thermal conductivity of polymers ${ }^{[20]}$, which is not very selective and a possible solution to reduce these reaction conditions is the use of catalyzed pyrolysis. Catalytic pyrolysis is an alternative to the recycling of pure or mixed plastics waste ${ }^{[30]}$. The catalyst can promote:

- decomposition reactions at low temperatures with lower energy consumption ${ }^{[15,20,36,38,39]}$;

- $\quad$ reduced costs ${ }^{[40]}$;

- increase the yield of products with higher added value $^{[20,38,40]}$;

- increase the process selectivity ${ }^{[39,41]}$;

- faster cracking reactions, leading to smaller residence times and reactors with smaller volumes ${ }^{[36]}$,

- inhibiting the formation of undesirable products ${ }^{[36]}$;

- inhibiting the formation of products consisting primarily of cyclic hydrocarbons, aromatic and branched, in the case of polyolefins catalytic cracking ${ }^{[36]}$;

- obtain liquid products with a lower boiling point range ${ }^{[33]}$.

Homogeneous and heterogeneous catalyst systems have been employed in the cracking polymers. In general, heterogeneous catalysts have been more used due to the ease of their separation and recovery of the reaction ${ }^{[36,39]}$. 
The homogeneous catalysts especially used are Lewis acids, as $\mathrm{AlCl}_{3}$, fused metal tetracloroaluminatos $\left(\mathrm{M}\left(\mathrm{AlCl}_{4}\right) \mathrm{n}\right)$, where the metal may be lithium, sodium, potassium, magnesium, calcium or barium and $\mathrm{n}$ can be 1 or 2$)^{[36]}$.

A wide variety of heterogeneous catalysts has been used and among them are: conventional solid acids (such as zeolites, silica-alumina, alumina and FCC catalysts (Fluid Catalytic Cracking)), mesostructured catalysts (such as MCM-41 etc.), nanocrystalline zeolites (such as n-HZSM-5), among others ${ }^{[25,35,36,39]}$.

Many studies have been carried out describing the cracking of pure polyolefins over various solid acids such as zeolites, clays, among others. The use of zeolites has been shown to be effective in improving the quality of products obtained in the pyrolysis of polyethylene and other addition polymers. The acidity of their active sites and its crystalline microporous structure (textural properties) favor hydrogen transfer reactions and thereby make them suitable for obtaining high conversions of gas at relatively low temperatures, between 350 and $500{ }^{\circ} \mathrm{C}^{[11,18,22,41-44]}$. That is, these features allow milder operating conditions (lower temperatures and reaction times) than a thermal pyrolysis ${ }^{[4,25,30,45]}$.

Differences in the catalytic activity of these solids are related to their acidic properties, especially the strength and number of acidic sites. The properties of these solid structures, as the specific area, particle size and pore size distribution, also have a crucial role in their performance, they control accessibility of voluminous molecules of the polyolefin internal catalytically active sites. While most work on catalytic cracking of polymers has been performed with pure polymers, it is accepted that the decomposition process can be affected by the presence of contaminants as well as chemical changes that occur in the polymer structure during use $\mathrm{e}^{[11,20,21,34,42,46]}$.

As mentioned, the catalyst pore size and acidity are important factors in the catalytic cracking of polymers ${ }^{[40,43,47]}$. Generally, the level of catalytic activity in the polyolefin pyrolysis increases with increasing the number of acidic sites. Thus, it is known that zeolite catalysts achieve higher conversions acids non-zeolitic catalysts ${ }^{[42]}$.

The mechanism of this process which involves the formation of a carbenium ion (isomerization, random chain scission and $\beta$ cleavage, hydrogen transfer, oligomerization / alkylation, aromatization) is influenced by the strength, density and distribution of the acid sites of the catalyst. This determines the products obtained in these reactions. Solid acid catalysts such as zeolites, favor hydrogen transfer reactions due to the presence of many acid $\operatorname{sites}^{[11,18,22,36,42,44]}$.

The acid strength of the solid is characterized by the presence of Lewis or Brønsted acid sites. In the case of crystalline solid acids, it is believed that most of the acid sites are located inside the pores of the material, as in the case of zeolites ${ }^{[1,42]}$.

Cracking is processed either by random chain scission (medium or weak acidity), for scission at the end of the chain (strong acidity) to give waxes and distillates (gasoil, gasoline) or light hydrocarbons (C3-C5 olefins), respectively. These primary cracking products may be removed from the reaction medium or subjected to secondary reactions (such as oligomerization, cyclization and aromatization).
The relative extent of these reactions is connected to the acidity and properties of catalyst, but also to experimental variables employed (such as reactor type, temperature, residence time, etc. $)^{[36]}$.

Catalysts having acidic sites on the surface and with the possibility of donating hydrogen ion increase rate of the isomerization products and increase the yield of hydrocarbon isomers and the quality of the fuel formed. Catalysts containing strong acid sites, higher density, are more effective in cracking polyolefins. However, the strong acidity and high pore size cause rapid deactivation of the catalyst. Thus, according to literature, it is preferable to carry out the pyrolysis of polyolefins in the presence of a catalyst with light acidity and long life $\mathrm{e}^{[33]}$.

Other types of catalysts which may be used in the pyrolysis process are catalysts with Lewis acid sites which are electron pair acceptors. As examples of such catalysts, there are $\mathrm{AlCl}_{3}, \mathrm{FeCl}_{3}, \mathrm{TiCl}_{4}$ and $\mathrm{TiCl}_{3}$, which are strong Lewis acids $^{[47]}$. These catalysts may be dissolved in molten polymer, which substantially increases the cracking efficiency while reducing its consumption. These types of catalysts have acidic sites on their surfaces that change the charge distribution in the carbon chain, making them capable of abstracting hydride ions of hydrocarbons to produce carbonium ions. This increases the catalytic effect, enabling a reduction in pyrolysis temperature and promoting the generation of ions for olefinic and aromatic compounds ${ }^{[32]}$.

However, the cost of the catalyst can greatly affect the economy of the process, even if it shows a good performance. To reduce this cost and make it even more attractive process, you can reuse the catalyst or use it in smaller quantities ${ }^{[23,42,48]}$. The biggest problem in the use of catalysts in the pyrolysis of plastics is that coke formation deactivates the catalyst over time, thereby decreasing its life cycle ${ }^{[33]}$.

\subsection{Comparison between thermal and catalytic pyrolysis}

Seo et al. ${ }^{[49]}$ studied the catalytic degradation of HDPE using a batch reactor at a temperature of $450{ }^{\circ} \mathrm{C}$. As shown in Table 1, the pyrolysis performed with the zeolite ZSM-5 had higher yield of the gaseous fraction and smaller liquid fraction when compared with thermal cracking. According to the authors, this is explained by the properties of the catalyst. Most zeolites, including ZSM-5, showed excellent catalytic efficiency in cracking, isomerization and aromatization due to its strong acidic property and its microporous crystalline structure. The ZSM-5 zeolite has a three-dimensional pore channel structure with pore size of $5.4 \times 5.6 \AA$ which allows an increased cracking of larger molecules, beyond

Table 1. Yield in thermal and catalytic pyrolysis of HDPE with ZSM-5 ${ }^{[49]}$.

\begin{tabular}{lccc}
\hline \multicolumn{1}{c}{ Product Yield (\% wt.) } & $\begin{array}{c}\text { Thermal } \\
\text { Pyrolysis }\end{array}$ & $\begin{array}{c}\text { Catalytic } \\
\text { Pyrolysis }\end{array}$ \\
\hline Gas Fraction & & 13.0 & 63.5 \\
\hline Liquid Fraction & Total & 84.0 & 35.0 \\
& $\mathrm{C}_{6}-\mathrm{C}_{12}$ & 56.55 & 99.92 \\
& $\mathrm{C}_{13}-\mathrm{C}_{23}$ & 37.79 & 0.08 \\
& $>\mathrm{C}_{23}$ & 5.66 & 0.0 \\
\hline Solid Fraction & & 3.0 & 1.5 \\
\hline
\end{tabular}


the high $\mathrm{Si} / \mathrm{Al}$ ratio which leads to an increase in thermal stability and acidity. Thus, initially degraded material on the external surface of the catalyst can be dispersed in the smaller internal cavities of the catalyst thus decomposed gaseous hydrocarbons (molecules with smaller sizes).

Marcilla et al. ${ }^{[34]}$ also used a batch reactor to evaluate the thermal and catalytic pyrolysis of HDPE and LDPE with HZSM-5 catalyst. The processing temperature was $550{ }^{\circ} \mathrm{C}$ and the results are shown in Table 2 . As can be seen, the condensable products were the major fraction for the thermal process and no solid fraction (coke) was detected. For the catalytic process an increase of the gas fraction, and this is due to the HZSM-5 catalyst present, which has strong and weak acid sites and an average pore size small. As mentioned above, this facilitates cracking leading to compounds with small sizes (gas fraction).

The results for the batch reactor are similar. However, there are studies where the values for each product obtained are different. This is because in this type of reactor the heat transfer is not as favored and, consequently, other factors such as the size and quantity of the sample or the carrier gas flow can determine the type of product formed. Moreover, in such reactors the extent of secondary reactions is smaller than the fluidized bed reactor. Using fixed beds where polymer and catalyst are contacted directly leads to problems of blockage and difficulty in obtaining intimate contact over the whole reactor. Without effective contact the formation of large amounts of residue are likely, and scale-up to industrial scale is not feasible ${ }^{[15]}$. The low thermal conductivity and high viscosity of the plastic may lead to a difficulty in mass transfer and heat. These factors influence the distribution of products, in conjuction with the operating conditions ${ }^{[50]}$.

\subsection{Zeolites}

Zeolites are microporous crystalline aluminosilicates of the elements of group 1A or 2A (especially sodium, potassium, magnesium and calcium), whose chemical composition can be represented as follows: $\mathrm{M}_{2} / \mathrm{nO} \cdot \mathrm{Al}_{2} \mathrm{O}_{3} \cdot \mathrm{ySiO}_{2} \cdot \mathrm{wH}_{2} \mathrm{O}$, where $\mathrm{y}$ varies from 2 to $10, \mathrm{n}$ is the valence of the cation and $\mathrm{w}$ is the amount of structural water ${ }^{[36]}$. Currently it is known the existence of minerals which have all essential requirements to be classified as zeolites, however, instead of aluminum (Al) and silicon ( $\mathrm{Si}$ ) occupying the tetrahedral positions are present elements such as phosphorus $(\mathrm{P})$, beryllium $(\mathrm{Be})$, among others ${ }^{[51,52]}$.

They are composed of tetrahedra of $\mathrm{SiO}_{4}, \mathrm{AlO}_{4}$ and $\mathrm{PO}_{4}$ as primary structural units, which are linked through oxygen atoms. Each oxygen atom is shared by two silicon or aluminum atoms, thus giving rise to a three-dimensional microporous structure ${ }^{[46,53]}$. The combination of these

Table 2. Yield of the thermal and catalytic pyrolysis of LDPE and HDPE with HZSM-5 ${ }^{[34]}$.

\begin{tabular}{lcccc}
\hline $\begin{array}{c}\text { Product Yield } \\
\text { (\% wt.) }\end{array}$ & LDPE & HDPE & $\begin{array}{c}\text { LDPE- } \\
\text { HZSM-5 }\end{array}$ & $\begin{array}{c}\text { HDPE- } \\
\text { HZSM-5 }\end{array}$ \\
\hline Gas Fraction & 14.6 & 16.3 & 70.7 & 72.6 \\
Liquid & 93.1 & 84.7 & 18.3 & 17.3 \\
Fraction/wax & & & & \\
Solid Fraction & - & - & 0.5 & 0.7 \\
\hline
\end{tabular}

two primary structures is found in the common zeolites, developing cavities of various shapes and sizes which are interconnected ${ }^{[42,51,53,54]}$.

The $\mathrm{AlO}_{4}$ tetrahedron has a negative charge of -1 , because the aluminum has a valence of +3 , which is less than the valence of +4 silicon. This charge is balanced by cations of alkali metals or alkaline earth metals (typically $\mathrm{Na}^{+}, \mathrm{K}^{+}$, $\mathrm{Ca}^{+2}$ or $\mathrm{Mg}^{+2}$ ) present inside the porous zeolite structure by means of cation exchange, may be replaced by other cations. When these cations are exchanged for protons, zeolite acid sites are formed. This exchange allows modification of the original properties of zeolites. The acidity of the zeolite can be the Brønsted acid type, proton donors or Lewis acid type, pair of electron acceptor ${ }^{[46,53]}$. These channels and cavities are occupied by ions, water molecules or other adsorbates which, due to high mobility, allow the ion exchange ${ }^{[51,53]}$.

The pore size corresponding to two-dimensional opening zeolite is determined by the number of tetrahedral atoms connected in sequence. The three-dimensional interactions lead to the most different geometries, forming from large internal cavities to a series of channels crossing the whole zeolite $^{[55]}$.

The pores of zeolites function as molecular sieves, blocking the free diffusion of large, bulky molecules inside the internal surface of the catalyst ${ }^{[41,54]}$. These molecular sieves combine high acidity with selectivity form. That is, are selective to separate molecules according to their shape and / or size, besides having a high specific area and high thermal stability to catalyze a variety of hydrocarbon reactions, including the cracking of polyolefins. The reactivity and the selectivity of zeolites as catalysts are determined by its high number of active sites, which are caused by an imbalance of charge between the silicon and aluminum atoms in the crystal, making the zeolite of the structural unit has a charge balance total least one ${ }^{[42,51]}$.

However, the process of rupture of the polymer molecules starts on the external surface of the zeolites, since the polymer chains must be broken before penetrating the internal pores of the zeolites, due to its small pore size. The zeolites have a specific pore size and the access of polymer molecules to internal reactive sites of the catalyst, as well as the final products within the pores are limited by their size. As mentioned, the catalyst pore size and acidity are important factors in the catalytic cracking of polymers ${ }^{[40,43,47]}$. Generally, the level of catalytic activity in the pyrolysis of polyolefins increases with increasing the number of acidic sites. Thus, it is known that zeolite catalysts achieve higher conversions than non-zeolitic catalysts acids ${ }^{[42]}$. In addition, branching of the polymer or end chain of polyethylene can penetrate the pores of the zeolites, reacting the acid sites located there and so increasing the activity ${ }^{[34]}$.

During the catalyzed pyrolysis, the polymer melts and is dispersed around the catalyst. The molten polymer is drawn into the spaces between the particles and therefore the active sites on the external surface of the catalyst. Reactions at the surface produce a low molecular weight materials, which are sufficiently volatile at the temperature of the reaction can diffuse through the polymer film as a product or may react even more in the pores. These reactions proceed via carbocation as transition state. The reaction rate is governed both by the nature of the carbocation formed as the nature and strength of the acid sites involved in catalysis. Regardless 
of how the carbocation is formed, it may be subjected to any of the following methods: load isomerization, the isomerization chain, hydride transfer, transfer of alkyl groups and formation and breaking of carbon-carbon bonds. As a result of this complex procedure, the product distribution reflects the action of the catalyst, which in turn is influenced by the size of its pores and for its chemical composition ${ }^{[34,56]}$.

The catalytic decomposition of the polyethylene occurs at the carbenium ion mechanism. The initial step occurs either by abstraction of the hydride ion (for Lewis acid sites) or by addition of a proton (the Brønsted acid sites) in the $\mathrm{C}-\mathrm{C}$ bonds of polyethylene molecules, or by thermal decomposition of polyolefins. Successive scission of the main chain occur to produce fragments having lower molecular weights than that of polyethylene. The resulting fragments are cracked or desidrociclizados in subsequent steps ${ }^{[18]}$.

The acid sites on the catalyst surface are responsible for the initiation of the carbocationic mechanism, which induces the degradation of polyethylene and polypropylene. As mentioned above, these acid sites are originated the generated load imbalance when $\mathrm{AlO}_{4}^{-}$is incorporated in the structure of zeolites. The content of $\mathrm{AlO}_{4}^{-}$determines the number of acid sites in the catalyst while topological factors related to its crystalline or amorphous structure influence the strength of these acidic centers. Textural characteristics control the access of molecules that are reacting in the catalytic sites. This accessibility is important in catalyzed reactions involving large molecules such as polymers ${ }^{[21,57]}$.

For presenting a microporous structure, zeolites have a higher internal surface than the external surface and this enables the mass transfer between these surfaces. However, the pore size is an important factor in this transfer, because only molecules with sizes smaller than these pores can enter or leave these spaces, which vary from one to another zeolite ${ }^{[53]}$.

Some chemical and physical characteristics of zeolites ensures them their catalytic capacity. Among these characteristics can be cited: high specific area and adsorption capacity; active sites (which may be acidic) whose strength and concentration can be directed to a specific application; size channels and cavities compatible with the size of many molecules and a network of canals and cavities that provides you with a selectivity of shape, selectivity to the reactant, product and transition state species ${ }^{[53]}$.

One of the factors that can affect the catalytic activity of zeolites is their deactivation by coke deposition on their channels. However, this coke formation rate depends on several factors, including: structure and acidity of the pores and the reaction conditions (such as temperature, pressure and nature of the reactants ${ }^{[53]}$.

The synthetic zeolites present some advantages and disadvantages in relation to natural zeolites. Among the advantages may be mentioned the purity, uniformity in size and shape of the channels and cavities, and a pre-defined chemical composition. The disadvantage has been their high cost and because of this, the synthetic zeolites are mainly intended for specific applications, where there is a need for a uniform composition and structure, for example, in the petroleum cracking process. Already the natural have a greater abundance and a lower cost of production, particularly if used in its in natura or if they require little beneficiation complex processes ${ }^{[51]}$.

\section{Conclusions}

Consumption of plastics has increased over the years and the concern with their waste generated too. Because of this many studies have been done with the aim to recover or recycle the waste.

Pyrolysis has been effective compared to other disposal methods, because it can reuse the energy and the raw materials contained in those waste, reducing thereby the environmental impacts caused by the inadequate disposal of these waste plastics.

The pyrolysis process may be thermal or catalytic. Thermal degradation occurs by radical mechanism, and as a result of this mechanism the products formed have a broad distribution of the number of carbon atoms in the main chain.

In this type of the endothermic process due to the low thermal conductivity of polymers, there is a need for high temperatures. Because of that there is a high expenditure of energy. In order to decrease this temperature, catalysts may be used.

With the catalytic pyrolysis, the products obtained have a more narrow distribution of the number of carbon atoms being directed to more specific products. The composition and amount of the obtained products are listed as type of catalyst used. Furthermore, the catalytic reaction decreases the degradation time and the fraction of solid waste formed.

Generally, the catalysts used in the catalytic degradation are solid acids such as zeolites. This type of degradation involves production of the intermediate carbenium ion by hydrogen transfer reactions. Zeolites used favor these reactions due to their sites acids that help in the process of breaking the polymer macromolecules. This breaking process begins on the surface of the zeolite, because the polymer needs to be broken into smaller molecules before entering the internal pores of these solids, due to the small size of their pores. Zeolites have a specific molecular pore size and access of such molecules to catalytic reactive sites, as well as growth of the final products within such pores is limited by its size.

The other experimental parameters such as temperature, reaction time, reactor type and flow of carrier gas also influence the composition of the products obtained. Pyrolysis can be carried out either for pure polymers or for polymer blends.

\section{References}

1. Mastral, J. F., Berrueco, C., \& Ceamanos, J. (2007). Theoretical prediction of product distribution of the pyrolysis of high density polyethylene. Journal of Analytical and Applied Pyrolysis, 80(2), 427-438. http://dx.doi.org/10.1016/j.jaap.2006.07.009.

2. Abbas-Abadi, M. S., Haghighi, M. N., \& Yeganeh, H. (2012). The effect of temperature, catalyst, different carrier gases and stirrer on the produced transportation hydrocarbons of LLDPE degradation in a stirred reactor. Journal of Analytical and Applied Pyrolysis, 95, 198-204. http://dx.doi.org/10.1016/j. jaap.2012.02.007.

3. Arabiourrutia, M., Elordi, G., Lopez, G., Borsella, E., Bilbao, J., \& Olazar, M. (2012). Characterization of the waxes obtained by the pyrolysis of polyolefin plastics in a conical spouted bed reactor. Journal of Analytical and Applied Pyrolysis, 94, 230-237. http://dx.doi.org/10.1016/j.jaap.2011.12.012. 
4. Coelho, A., Costa, L., Marques, M. M., Fonseca, I. M., Lemos, M. A. N. D. A., \& Lemos, F. (2012). The effect of ZSM-5 zeolite acidity on the catalytic degradation of highdensity polyethylene using simultaneous DSC/TG analysis. Applied Catalysis A: General, 413-414, 183-191. http://dx.doi. org/10.1016/j.apcata.2011.11.010.

5. Abbas-Abadi, M. S., Haghighi, M. N., \& Yeganeh, H. (2013). Evaluation of pyrolysis products of virgin high density polyethylene degradation using different process parameters in a stirred reactor. Fuel Processing Technology, 109, 90-95. http://dx.doi.org/10.1016/j.fuproc.2012.09.042.

6. Stelmachowski, M. (2010). Thermal conversion of waste polyolefins to the mixture by hydrocarbons in the reactor with molten metal bed. Energy Conversion and Management, 51(10), 2016-2020. http://dx.doi.org/10.1016/j.enconman.2010.02.035.

7. Miskolczi, N., \& Nagy, R. (2012). Hydrocarbons obtained by waste plastic pyrolysis: comparative analysis of decomposition described by different kinetic models. Fuel Processing Technology, 104, 96-104. http://dx.doi.org/10.1016/j.fuproc.2012.04.031.

8. Demirbas, A. (2004). Pyrolysis of municipal of plastic wastes for recovery of gasoline-range hydrocarbons. Journal of Analytical and Applied Pyrolysis, 72(1), 97-102. http://dx.doi. org/10.1016/j.jaap.2004.03.001

9. Valle, M. L. M., Guimarães, M. J. O. C., \& Sampaio, C. M. S. (2004). Degradação de poliolefinas utilizando catalisadores zeólitas. Polímeros: Ciência e Tecnologia, 1(14), 17-21. http:// dx.doi.org/10.1590/S0104-14282004000100009.

10. Shah, S. H., Khan, Z. M., Raja, I. A., Mahmood, Q., Bhatti, Z. A., Khan, J., Farooq, A., Rashid, N., \& Wu, D. (2010). Low temperature conversion of plastic waste into light hydrocarbons. Journal of Hazardous Materials, 179(1-3), 15-20. http://dx.doi. org/10.1016/j.jhazmat.2010.01.134. PMid:20172649.

11. Panda, A. K., Singh, R. K., \& Mishra, D. K. (2010). Thermolysis of waste plastics to liquid fuel. A suitable method for plastic waste management and manufacture of value added products: a world prospective. Renewable \& Sustainable Energy Reviews, 14(1), 233-248. http://dx.doi.org/10.1016/j.rser.2009.07.005.

12. Al-Salem, S. M., Lettieri, P., \& Baeyens, J. (2009). Recycling and recovery routes of plastic solid waste (PSW): a review. Waste Management (New York, N.Y.), 29(10), 2625-2643. http:// dx.doi.org/10.1016/j.wasman.2009.06.004. PMid:19577459.

13. Spinacé, M. A. S., \& De Paoli, M. A. (2005). A tecnologia da reciclagem de polímeros. Quimica Nova, 98(1), 65-72. http:// dx.doi.org/10.1590/S0100-40422005000100014.

14. Singhabhandhu, A., \& Tezuka, T. (2010). The waste-to-energy framework for integrated multi-waste utilization: waste cooking oil, waste lubricating oil, and waste plastics. Energy, 35(6), 2544-2551. http://dx.doi.org/10.1016/j.energy.2010.03.001.

15. Lin, Y.-H., \& Yang, M.-H. (2008). Tertiary recycling of polyethylene waste by fluidized-bed reactions in the presence of various cracking catalysts. Journal of Analytical and Applied Pyrolysis, 83(1), 101-109. http://dx.doi.org/10.1016/j. jaap.2008.06.004.

16. Huang, W.-C., Huang, M.-S., Huang, C.-F., Chen, C.-C., \& Ou, K.-L. (2010). Thermochemical conversion of polymer wastes into hydrocarbon fuels over various fluidizing cracking catalysts. Fuel, 89(9), 2305-2316. http://dx.doi.org/10.1016/j. fuel.2010.04.013.

17. López, A., De Marco, I., Caballero, B. M., Adrados, A., \& Laresgoiti, M. F. (2011). Deactivation and regeneration of ZSM-5 zeolite in catalytic pyrolysis of plastic wastes. Waste Management (New York, N.Y.), 31(8), 1852-1858. http://dx.doi. org/10.1016/j.wasman.2011.04.004. PMid:21530221.

18. Park, D. W., Hwang, E. Y., Kim, J. R., Choi, J. K., Kim, Y. A., \& Woo, H. C. (1999). Catalytic degradation of polyethylene over solid acid catalysts. Polymer Degradation \& Stability, 65(2), 193-198. http://dx.doi.org/10.1016/S0141-3910(99)00004-X.

19. Lin, Y.-H., \& Yang, M.-H. (2005). Catalytic reactions of postconsumer polymer waste over fluidized cracking catalysts for producing hydrocarbons. Journal of Molecular Catalysis A Chemical, 231(1-2), 113-122. http://dx.doi.org/10.1016/j. molcata.2005.01.003.

20. Achilias, D. S., Roupakias, C., Megalokonomos, P., Lappas, A. A., \& Antonakou, E. V. (2007). Chemical recycling of plastic wastes made from polyethylene (LDPE and HDPE) and polypropylene (PP). Journal of Hazardous Materials, 149(3), 536-542. http://dx.doi.org/10.1016/j.jhazmat.2007.06.076. PMid:17681427.

21. Aguado, J., Serrano, D. P., San Miguel, G., Escola, J. M., \& Rodríguez, J. M. (2007). Catalytic activity of zeolitic and mesostructured catalysts in the cracking of pure and waste polyolefins. Journal of Analytical and Applied Pyrolysis, 78(1), 153-161. http://dx.doi.org/10.1016/j.jaap.2006.06.004.

22. Serrano, D. P., Aguado, J., Escola, J. M., \& Rodríguez, J. M. (2005). Influence of nanocrystalline HZSM-5 external surface on the catalytic cracking of polyolefins. Journal of Analytical and Applied Pyrolysis, 74(1-2), 353-360. http:// dx.doi.org/10.1016/j.jaap.2004.11.037.

23. Lin, H.-T., Huang, M.-S., Luo, J.-W., Lin, L.-H., Lee, C.-M., \& Ou, K.-L. (2010). Hydrocarbon fuels produced by catalytic pyrolysis of hospital plastic wastes in a fluidizing cracking process. Fuel Processing Technology, 91(11), 1355-1363. http://dx.doi.org/10.1016/j.fuproc.2010.03.016.

24. López, A., De Marco, I., Caballero, B. M., Laresgoiti, M. F., \& Adrados, A. (2010). Pyrolysis of municipal wastes: influence of raw material composition. Waste Management (New York, N.Y.), 30(4), 620-627. http://dx.doi.org/10.1016/j. wasman.2009.10.014. PMid:19926462.

25. Sakata, Y., Uddin, M.A., \& Muto, A. (1999). Degradation of polyethylene and polypropylene into fuel oil by using solid acid and non-acid catalysts. Journal of Analytical and Applied Pyrolysis, 51(1-2), 135-155.

26. Lee, S.Y., Yoon, J.H., Kim, J.R., \& Park, D.W. (2001). Catalytic degradation of polystyrene over natural clinoptilolite zeolita. Polymer Degradation and Stability, 74(2), 297-305.

27. Hernández, M. R., Garcia, A. N., \& Marcilla, A. (2005). Study of the gases obtained in thermal and catalytic flash pyrolysis of HDPE in a fluidized bed reactor. Journal of Analytical and Applied Pyrolysis, 73(2), 314-322. http://dx.doi.org/10.1016/j. jaap.2005.03.001.

28. Buekens, A. (2006). Introduction to feedstock recycling of plastics. In J. Scheirs, \& W. Kaminsky (Orgs.), Feedstock recycling and pyrolysis of waste plastics (pp. 3-42). Hoboken: John Wiley \& Sons.

29. Silvério, F. O., Barbosa, L. C. A., \& Piló-Veloso, D. (2008). A pirólise como técnica analítica. Quimica Nova, 31(6), 15431552. http://dx.doi.org/10.1590/S0100-40422008000600045.

30. Lopez-Urionabarrenechea, A., De Marco, I., Caballero, B. M., Laresgoiti, M. F., \& Adrados, A. (2012). Catalytic stepwise pyrolysis of packaging plastic waste. Journal of Analytical and Applied Pyrolysis, 96, 54-62. http://dx.doi.org/10.1016/j. jaap.2012.03.004.

31. Singh, S., Wu, C., \& Williams, P. (2012). Pyrolysis of waste materials using TGA-MS and TGA-FTIR as complementary characterization techniques. Journal of Analytical and Applied Pyrolysis, 94, 99-107. http://dx.doi.org/10.1016/j. jaap.2011.11.011.

32. Donaj, P. J., Kaminsky, W., Buzeto, F., \& Yang, W. (2012). Pyrolysis of polyolefins for increasing the yield of monomers' recovery. Waste Management (New York, N.Y.), 32(5), 840-846. http://dx.doi.org/10.1016/j.wasman.2011.10.009. PMid:22093704. 
33. Scheirs, J. (2006). Overview of commercial pyrolysis processes for waste plastics. In J. Scheirs, \& W. Kaminsky (Orgs.), Feedstock recycling and pyrolysis of waste plastics (pp. 383434). Hoboken: John Wiley \& Sons.

34. Marcilla, A., Beltrán, M. I., \& Navarro, R. (2009). Thermal and catalytic pyrolysis of polyethylene over HZSM5 and HUSY zeolites in a batch reactor under dynamic conditions. Applied Catalysis B: Environmental, 86(1-2), 78-86. http:// dx.doi.org/10.1016/j.apcatb.2008.07.026.

35. Lee, K.-H. (2012). Effects of the types of zeolites on catalytic upgrading of pyrolysis wax oil. Journal of Analytical and Applied Pyrolysis, 94, 209-214. http://dx.doi.org/10.1016/j. jaap.2011.12.015.

36. Aguado, J., Serrano, D. P., \& Escola, J. M. (2006). Catalytic upgrading of plastic wastes. In J. Scheirs, \& W. Kaminsky (Orgs.), Feedstock recycling and pyrolysis of waste plastics (pp. 73-110). Hoboken: John Wiley \& Sons.

37. Lee, K.-H. (2006). Thermal and catalytic degradation of waste HDPE. In J. Scheirs, \& W. Kaminsky (Orgs.), Feedstock recycling and pyrolysis of waste plastics (pp. 129-160). Hoboken: John Wiley \& Sons.

38. Murata, K., Brebu, M., \& Sakata, Y. (2010). The effect of silicaalumina catalysts on degradation of polyolefins by a continuous flow reactor. Journal of Analytical and Applied Pyrolysis, 89(1), 30-38. http://dx.doi.org/10.1016/j.jaap.2010.05.002.

39. Liu, W., Hu, C., Yang, Y., Tong, D., Li, G., \& Zhu, L. (2010). Influence of ZSM-5 zeolite on the pyrolytic intermediates from the co-pyrolysis of pubescens and LDPE. Energy Conversion and Management, 51(5), 1025-1032. http://dx.doi.org/10.1016/j. enconman.2009.12.005.

40. White, R. L. (2006). Acid-catalyzed cracking of polyolefins: primary reaction mechanism. In J. Scheirs, \& W. Kaminsky (Orgs.), Feedstock recycling and pyrolysis of waste plastics (pp. 45-72). Hoboken: John Wiley \& Sons.

41. Mastral, J. F., Berrueco, C., Gea, M., \& Ceamanos, J. (2006). Catalytic degradation of high density polyethylene over nanocrystalline HZSM-5 zeolite. Polymer Degradation \& Stability, 91(12), 3330-3338. http://dx.doi.org/10.1016/j. polymdegradstab.2006.06.009.

42. Ofoma, I. (2006). Catalytic pyrolysis of polyolefins. Atlanta: Georgia Institute of Technology.

43. Li, X., Shen, B., Guo, Q., \& Gao, J. (2007). Effects of large pore zeolite additions in the catalytic pyrolysis catalyst on the light olefins production. Catalysis Today, 125(3-4), 270-277. http://dx.doi.org/10.1016/j.cattod.2007.03.021.

44. Miskolczi, N., \& Bartha, L. (2008). Investigation of hydrocarbon fractions form waste plastic recycling by FTIR, GC, EDXRFS and SEC techniques. Journal of Biochemical and Biophysical Methods, 70(6), 1247-1253. http://dx.doi.org/10.1016/j. jbbm.2007.05.005. PMid:17602751.

45. Elordi, G., Olazar, M., Aguado, R., Lopez, G., Arabiourrutia, M., \& Bilbao, J. (2007). Catalytic pyrolysis of high density polyethylene in a conical spouted bed reactor. Journal of Analytical and Applied Pyrolysis, 79(1-2), 450-455. http:// dx.doi.org/10.1016/j.jaap.2006.11.010.
46. Manos, G. (2006). Catalytic degradation of plastic waste to fuel over microporus materials. In J. Scheirs, \& W. Kaminsky (Orgs.), Feedstock recycling and pyrolysis of waste plastics (pp. 193-208). Hoboken: John Wiley \& Sons.

47. Kaminsky, W., \& Zorriqueta, I.-J. N. (2007). Catalytical and thermal pyrolysis of polyolefins. Journal of Analytical and Applied Pyrolysis, 79(1-2), 368-374. http://dx.doi.org/10.1016/j. jaap.2006.11.005.

48. López, A., De Marco, I., Caballero, B. M., Laresgoiti, M. F., Adrados, A., \& Aranzabal, A. (2011). Catalytic pyrolysis of plastic wastes with two different types of catalysts: ZSM-5 zeolite and Red Mud. Applied Catalysis B: Environmental, 104(3-4), 211-219. http://dx.doi.org/10.1016/j.apcatb.2011.03.030.

49. Seo, Y.-H., Lee, K.-H., \& Shin, D.-H. (2003). Investigation of catalytic degradation of high-density polyethylene by hydrocarbons group type analysis. Journal of Analytical and Applied Pyrolysis, 70(2), 383-398. http://dx.doi.org/10.1016/ S0165-2370(02)00186-9.

50. Lin, Y.-H. (2009). Production of valuable hydrocarbons by catalytic degradation of a mixture of post-consumer plastic waste in a fluidized-bed reactor. Polymer Degradation \& Stability, 94(11), 1924-1931. http://dx.doi.org/10.1016/j. polymdegradstab.2009.08.004.

51. Monte, M. B. M., \& Resende, N. G. A. M. (2005). Zeolitas naturais. In A. B. Luz, \& F. A. F. Lins, Rocha e minerais industriais: usos e especificações (pp. 699-720). Rio de Janeiro: CETEM

52. Letichevsky, S. (2008). Sintese e caracterização das zeolitas mordenita, ferrierita e ZSM-5 nanocristalinas (Tese de doutorado). Pontifícia Universidade Católica do Rio de Janeiro, Rio de Janeiro.

53. Tourinho, R.R.C. (2009). Estudo da acidez de zeolitas impregnadas com platina utilizando reações de troca $H / D$ com aromáticos e correlações lineares de energia livre (Dissertação de mestrado). Universidade Federal do Rio de Janeiro, Rio de Janeiro.

54. Aksoy, Y. Y. (2010). Characterization of two zeolites for geotechnical and geoenvironmental applications. Applied Clay Science, 50(1), 130-136. http://dx.doi.org/10.1016/j. clay.2010.07.015.

55. Braga, A. A. C., \& Morgon, N. H. (2007). Descrições estruturais cristalinas de zeolitos. Quimica Nova, 30(1), 178-188. http:// dx.doi.org/10.1590/S0100-40422007000100030.

56. Pinto, F., Costa, P., Gulyurtlu, I., \& Cabrita, I. (1999). Pyrolysis of plastic wastes 2. Effect of catalyst on product yield. Journal of Analytical and Applied Pyrolysis, 51, 57-71.

57. Hwang, E.-Y., Kim, J.-R., Choi, J.-K.; Woo, H.-C., \& Park, D.-W. (2002). Performance of acid treated natural zeolitas in catalytic degradation of polypropylene. Journal of Analytical and Applied Pyrolysis, 62(2), 351-364.

Received: Mar. 31, 2015 Revised: July 08, 2015 Accepted: Aug. 31, 2015 